\title{
Erratum to: The vascular access in the elderly: a position statement of the Vascular Access Working Group of the Italian Society of Nephrology
}

\author{
Carlo Lomonte ${ }^{1} \cdot$ Giacomo Forneris $^{2} \cdot$ Maurizio Gallieni $^{3} \cdot$ Luigi Tazza $^{4}$. \\ Mario Meola $^{5,6} \cdot$ Massimo Lodi $^{7} \cdot$ Massimo Senatore $^{8} \cdot$ Walter Morale $^{9}$. \\ Monica Spina $^{10} \cdot$ Marcello Napoli $^{11} \cdot$ Decenzio Bonucchi $^{12} \cdot$ Franco Galli $^{13}$
}

Published online: 26 May 2017

(C) Italian Society of Nephrology 2017

\section{Erratum to: J Nephrol (2016) 29:175-184 \\ DOI 10.1007/s40620-016-0263-z}

The article was originally published Online First without open access. After publication in volume 29, issue 2, pages 175-184 the author decided to opt for Open Choice and to make the article an open access publication. Therefore, the copyright of the article has been changed to ()$^{\circ}$ The
Author(s) [2017] and the article is forthwith distributed under the terms of the Creative Commons Attribution 4.0 International License (http://creativecommons.org/licenses/ by/4.0/), which permits use, duplication, adaptation, distribution and reproduction in any medium or format, as long as you give appropriate credit to the original author(s) and the source, provide a link to the Creative Commons license, and indicate if changes were made.

The online version of the original article can be found under doi:10.1007/s40620-016-0263-z.

Carlo Lomonte

carlolomonte@libero.it

1 U.O.C. di Nefrologia e Dialisi, Ente Ecclesiastico Ospedale "F.Miulli”, 70021 Acquaviva delle Fonti, Italy

2 Struttura Complessa a Direzione Universitaria di Nefrologia e Dialisi, Ospedale Giovanni Bosco, Turin, Italy

3 Unità di Nefrologia e Dialisi, Ospedale San Carlo, Milan, Italy

4 Dipartimento di Scienze Chirurgiche, Policlinico Gemelli, Università Cattolica Sacro Cuore, Rome, Italy

5 Dipartimento di Medicina, Università di Pisa, Pisa, Italy

6 Scuola Superiore Sant'Anna, Pisa, Italy

7 Unità di Nefrologia e Dialisi, Ospedale Santo Spirito, Pescara, Italy
8 U.O.C. di Nefrologia e Dialisi, Ospedale Annunziata, Cosenza, Italy

9 Unità di Nefrologia e Dialisi, A.O. Cannizzaro, Catania, Italy

10 Unità di Nefrologia e Dialisi, Ospedale San Gavino Monreale, Cagliari, Italy

11 U.O.C. di Nefrologia e Dialisi, Ospedale Santa Caterina Novella, Galatina, Italy

12 Unità di Nefrologia e Dialisi, Ospedale di Carpi, Carpi, Italy

13 Unità di Nefrologia IRCCS, Fondazione Salvatore Maugeri, Pavia, Italy 